\title{
PLASTICIFICATION OF LEATHER SEMIFINISHED CHROME TANNING USING BIOCATALITIC MODIFIER
}

\author{
Anatoliy Danylkovych \\ Department of Biotechnology, leather and fur \\ Kyiv National University of Technologies and Design \\ 2 Nemirovich-Danchenko str., Kyiv, Ukraine, 01011 \\ ag101@ukr.net \\ Sergiy Bilinskiy \\ Department of Biotechnology, leather and fur \\ Kyiv National University of Technologies and Design \\ 2 Nemirovich-Danchenko str., Kyiv, Ukraine, 01011 \\ bilinskiy.s.o@gmail.com \\ Yiliia Potakh \\ Department of Biotechnology, leather and fur \\ Kyiv National University of Technologies and Design \\ 2 Nemirovich-Danchenko str., Kyiv, Ukraine, 01011 \\ uliyapotakh@gmail.com
}

\begin{abstract}
The aim of the work is studying the plasticization process of semi-finished chrome tanning from hides of cattle for the production of elastic leather materials.

The process of influence of biologically catalytic modifiers on the elastic properties of the leather semi-finished chrome tiling is investigated. The technological parameters of the process of plasticization-filling of leather semi-finished products are determined. The developed plasticisation process of leather semi-finished products using biocatalytic modifier 3 and aerosol A-300 provides the formation of natural leather materials with high elastic-plastic properties while saving chemical materials by $20-25 \%$. The resulting full-fledged leather material according to the complex of properties meets the requirements for elastic leather materials for garments according to DSTU 3115-95, the interstate standard for leather for the top of shoes "GOST 939-88" and the requirements of the international standard of quality management systems "ISO 9001:2008".

Thus, the technology of plasticization-filling of leather semi-finished product was developed, which allows to increase the yield of leather material to $6.7 \%$ compared with the existing technology.

Keywords: semi-finished product of chrome tanning, plasticization of semi-finished product, biocatalytic modifier, skin properties.

\section{Introduction}

Modern technologies for the processing of leather raw materials into highly elastic leather materials must meet the requirements for material and energy consumption, reduce the cost of production and environmental safety of production. In this respect, the improvement of existing technologies and the development of new ones makes it possible to use shortages of natural raw materials more efficiently, to replace imported high-value reagents with domestic scientifically sound and environmentally friendly. In this regard, the increase in the elastic properties of leather materials makes it possible to expand the assortment and their polyfunctional use in various fields.

For the formation of highly elastic leather materials, a wide range of chemical and biologically active reagents of various compositions are used. It is envisaged to provide increased mobility of elements of the fiber structure of leather materials to maintain a complex of important operational properties in the finished material. It is known to use palm oil with a modified silicone compound which molecules contain end hydroxyl groups followed by esterification by maleate anhydride and sodium bisulfite [1] for plasticization of clothing skins. For the production of a wide range of soft leather materials by TFL, a plasticizer anionic composition Coripol ALF based on lecithin has been developed, which includes natural and synthetic components [2]. The developed means have 
low viscosity and provide high stability and increased light and heat resistance of leather material. The work [3] shows the advantages of polyamide carboxylic acid before a traditional fat emulsion. Specialists from Lanxess recommend this reagent as a universal plasticizer for clothing, footwear, furniture, leather haberdashery and automotive skins. In this case, the stability of natural material to the effect of light and heat, high intensity of coloration during dyeing, as well as biodegradation of the developed plasticizer is determined.

Plasticization of the structure of leather raw fresh dry method of preservation occurs through the use of biologically active reagents [4]. At the same time, the defects of the skin are reduced during machining. For this purpose, bioactive preparations Lithudac LI Novo Bate WB are used at the stage of skin leather stripping [5], and at the stage of removal of natural fatty acids alkaline lipases or a combination thereof with alkaline proteases are used.

The influence of copolymers on the basis of ethyl- and butyl acrylate on the physical and mechanical properties of leather semi-finished products [6] was investigated. Increased elastic-plastic indices of leather material have been established. In the work [7], the plasticization effect is shown when using compositions based on poly(butyl) acrylate and polyethylene glycol in the manufacture of leather and parchment. The authors explain this effect by blocking the functional groups of the dermis collagen and the weakening of the intermolecular interactions of the elements of its supramolecular structure. In contrast to acrylic polymer emulsions, amilofurazan formaldehyde resin, modified with isopropyl alcohol, also makes it possible to reduce the reduction of the half-finished product when it is dried [8]. The use of a composition comprising montmorillonite and polyacrylic acid $[9,10]$ allows the formation of skin with a high orientation ability of the fibrous structure of the material during deformation.

Thus, due to the complex hierarchical structure of leather raw materials [11], for the plasticization of natural materials, appropriate chemical reagents, including biologically active modifiers of collagen structure, should be used. It should be noted that the effective use of leather raw materials in the works considered practically does not pay due attention.

The aim of this work is studying the plasticization process of semi-finished chrome tanning from hides of cattle for the production of elastic leather materials, which will ensure the formation of genuine leather with high elastic-plastic properties. In this work the following tasks are foreseen:

- choice of biocatalytic modifiers BCM of collagen structure;

- influence of BCM expenditures on elastic-plastic properties of leather semi-finished products;

- determination of optimal temperature action of BCM on the structural and mechanical properties of leather semi-finished products;

- implementation of plasticization action of BCM in the manufacture of leather material in semi-manufactured conditions.

\section{Materials and methods}

In order to formulate the experiment in laboratory conditions, a half-finished chrome tile was planted on a thickness of $1.4 \mathrm{~mm}$ with a temperature of hydrothermal stability of $109{ }^{\circ} \mathrm{C}$, obtained from the laboring area of raw material of cattle - wet salting bull. In this case, lots of samples in the amount of eight pieces in size $10 \times 18 \mathrm{~cm}$ were selected by the method of asymmetric furnace [12]. In semi-manufactured conditions for study, half-finished skins were used after a planning on a thickness of $1.3 \mathrm{~mm}$, selected in a batch by the method of alternating half-halves.

Biocatalytic modifier was plasticizers of hydrolytic action, obtained from Bac cultures Bacillus subtilis i Aspergillus awamori [13]. In this case, BCM-3 is a mixture of two modifiers at a ratio of $1: 1$.

Before plasticization, the half-finished product of chromium tanning was neutralized to a $\mathrm{pH}$ of 5.4 by means of formate and sodium bicarbonate at a ratio of $1 / 1$, washed with increasing water temperature, depending on the plasticization conditions, to $65-85{ }^{\circ} \mathrm{C}$ with a water/half-finished product ratio of $1 / 1.5$ over $10-15 \mathrm{~min}$. Plasticization of the semi-finished product was performed for 20 minutes. Then, the temperature of the technological solution was reduced to $53-55^{\circ} \mathrm{C}$ with the addition of water at a temperature of $19-21{ }^{\circ} \mathrm{C}$ for further plastering with corrosion dusts DL (Trumpler, Germany) at a consumption of 7-6\% of the mass of semi-finished product (option 1 
and 2 respectively) for 30-40 minutes. (Table 1) At the same time, the preparation on the basis of the phenolic compounds of the trupon $\mathrm{G}$ of the Trumpler firm (Germany) and the quebracho extract (China) was used.

Table 1

Composition of the plasticization and filling composition

\begin{tabular}{cccc}
\hline Indicator & Value of Technology Indicator \\
experimental 2 & active \\
\hline BCM-3 & 0,2 & 0,2 & 0 \\
Aerosil A-300 & 0 & 1 & 0 \\
The reagent is a trupon DL & 7 & 6 & 7 \\
Relugan D & 0 & 0 & 2 \\
Trupon G. & 2 & 2 & 3 \\
Quebracho extract & 5 & 5 & 6
\end{tabular}

In second version, the half-finished product is in 5 minutes before the introduction of the grease material was treated with a dispersion of highly dispersed silicon oxide (II) - aerosil A-300, which is produced by Kalush Chemical and Metallurgical Plant (Ukraine). The active technology uses a condensation preparation based on melanin, relugan D of BASF (Germany).Processing of the samples was completed by fixation of the plasticizer in the structure of the semi-finished product as a result of a decrease in the $\mathrm{pH}$ of the working solution by aluminum-potassium alumina to 4.0-4.2, followed by washing for 10 minutes. The samples were plasticized only with gum.

The batches of semi-finished products were processed in a capacity of $10 \mathrm{dm}^{3}$ with built-in shelves for their mixing at a continuous rotation at a speed of $18-20 \mathrm{~min}^{-1}$ at the installation of a ball-bearing two-valve mill M-188-01. The plasticized semi-finished product was subsequently subjected to drying-moisturizing treatments with an increase in moisture content to content of $13-15 \%$.

In semi-industrial conditions, the water consumption for plasticization of the semi-finished product was reduced to a ratio of $1 / 1$, and the process was carried out in a drum of the Doze company (Germany) with a volume of $0.39 \mathrm{~m}^{3}$ (Fig. 1) at a temperature of $71-75^{\circ} \mathrm{C}$. In addition, the semi-finished product after plasticization of BCM-3 by the experimental technology 2 was subjected to filling using $1.0 \%$ of fine silicon oxide (II) grade aerosol A-300 with the size of primary particles of 4-50 nm. and a specific surface area of 50-380 $\mathrm{m}^{2} / \mathrm{g}[14,15], 2 \%$ of the auxiliary synthetic duster of trupon $\mathrm{G}$ (Trumpler, Germany) and $5 \%$ tannide of quebracho extract per active substance. To complete the filling process, formic acid was used after its dilution with water 1/10.

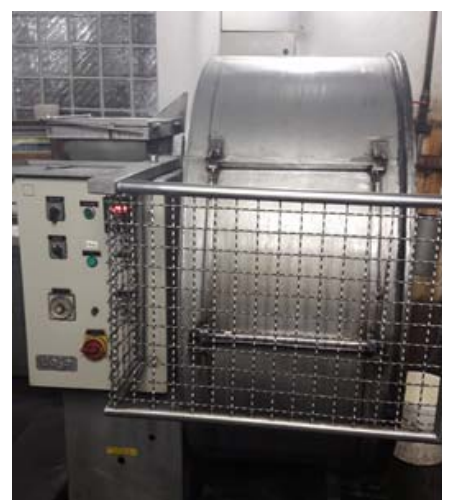

Fig. 1. The drum of the experimental department of public JSC Chynbar

The chemical composition of the filled semi-finished product and its physical and mechanical parameters were determined by the methods [12]. At the same time, the mechanical indices of the obtained semi-finished product were measured using a device for determining the rigidity of PZHU-12M (ПЖУ-12M) and a breaking machine RT-250M (PT-250) at a sample deformation 
rate of $90 \mathrm{~mm} / \mathrm{min}$. The output of the semifinished area was determined on the electromechanical measuring machine model 07179/P1 of Svit firm (Czech Republic).

\section{Results and discussion}

Taking into account the complex of physicochemical and biological characteristics of biocatalytic modifiers of the leather collagen structure, studies of the effect of their expenditures on the physical and mechanical properties of leather semi-finished chrome tanning (Table 2) have been carried out. As can be seen from the above data, with the increase in the content of BCM-1 and BCM-2 in the working solution at a temperature of $75^{\circ} \mathrm{C}$, the stiffness of the material decreases already at a consumption of $0.1 \%$ of the mass of the half-finished product. This effect is more pronounced for BCM-1 reagent. At the same time, the durability is practically unchanged. In the case of BCM-3, the effect of reducing stiffness and, accordingly, increasing the elasticity of leather material is expressed more strongly than each collagen modifier used separately. It should be noted that the absolute value of the rigidity of the material plasticized BCM-3 at a rate of 0.1 and $0.2 \%$, respectively, decreases in 1.7 and 2.1 times compared with the control samples.

Table 2

Physical and mechanical properties of plasticized semi-finished products

\begin{tabular}{cccccc}
\hline \multirow{2}{*}{ Consumption Modifier } & \multicolumn{7}{c}{ BCM, \% by weight of semi-finished product } \\
& $\mathbf{0}$ & $\mathbf{0 , 1}$ & $\mathbf{0 , 2}$ & $\mathbf{0 , 3}$ & $\mathbf{0 , 5}$ \\
\hline BCM-1 & $41,0 / 19,4$ & $30,0 / 19,0$ & $28,0 / 21,0$ & $27,0 / 20,3$ & $27,0 / 17,5$ \\
BCM-2 & $40,0 / 19,0$ & $33,0 / 18,8$ & $32,0 / 20,0$ & $32,0 / 19,8$ & $31,0 / 18,0$ \\
BCM-3 & $40,0 / 19,2$ & $23,0 / 19,7$ & $19,0 / 21,5$ & $18,0 / 19,6$ & $18,0 / 17,2$
\end{tabular}

Note: numerator and denominator correspond to indicators of rigidity, $S N$, and strength limits, $M P a$

The influence of the temperature of the plasticization process of leather semi-finished products by various biocatalytic modifiers at a flow rate of $0.2 \%$ by weight of the half-finished product on its elastic properties is given in Table 3. In the considered temperature range there is a decrease in stiffness and increase elasticity of samples for all modifiers, especially when using BCM-3. In this case, at temperatures of $81-85^{\circ} \mathrm{C}$, the stiffness decreases by 2.35 times, and the elongation at a stress of $10 \mathrm{MPa}$ increases by $35 \%$ compared with the control sample. It should be noted that when processing leather material at a temperature above $75^{\circ} \mathrm{C}$, the elastic-plastic characteristics are practically.

In addition, the strength of the plasticized semi-finished product with the use of BCM slightly increases compared to the control sample, especially this is noticeable for BCM-3, and reaches $17.0 \%$ (Fig. 2). This also applies to the tearing elongation of the plasticized semi-finished product (Fig. 3).

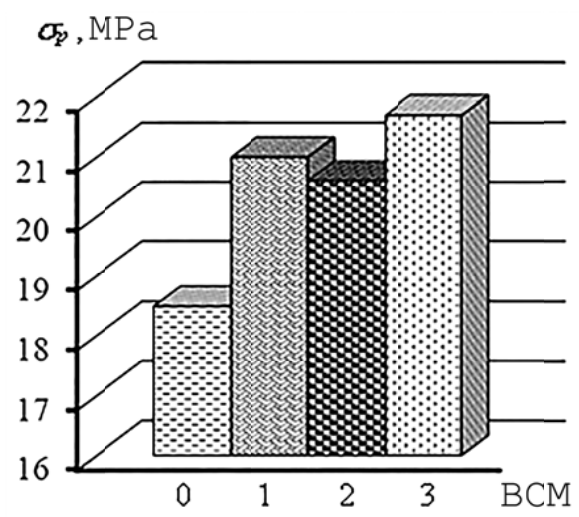

Fig. 2. The dependence of the strength limit of the leather semi-finished product $\sigma_{p}$, from the type of biocatalytic modifier 


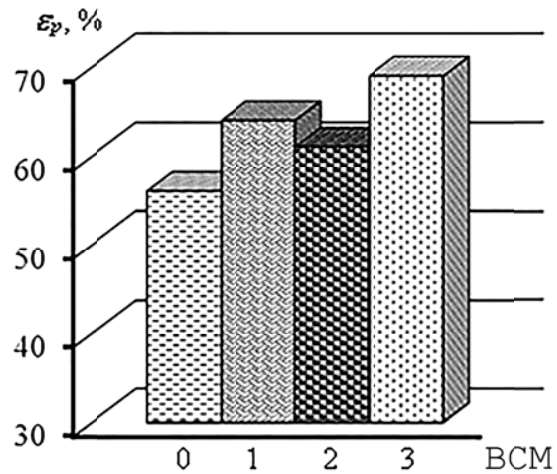

Fig. 3. The dependence of elongation at a break $\varepsilon_{p}$, from the type of biocatalytic modifier

Approbation of biologically catalytic technology was carried out in the conditions of the research workshop of public joint-stock company "Chynbar". When plasticizing-filling of leather semi-finished products, the composition of which is shown in Table 3.

Table 3

Physical and mechanical properties of plasticized semi-finished products at different temperatures

\begin{tabular}{cclcc}
\hline & & \multicolumn{2}{c}{ Consumption Modifier } \\
Temperature, ${ }^{\circ} \mathbf{C}$ & Without BCM & BCM-1 & BCM-2 & BCM-3 \\
\hline $61-65$ & $40,0 / 26,6$ & $29,7 / 30,1$ & $34,7 / 28,3$ & $24,3 / 32,0$ \\
$66-70$ & $39,0 / 26,2$ & $28,5 / 30,6$ & $33,2 / 28,9$ & $23,0 / 33,5$ \\
$71-75$ & $39,0 / 27,4$ & $27,9 / 31,5$ & $31,7 / 29,8$ & $20,0 / 34,3$ \\
$76-80$ & $40,3 / 27,0$ & $27,0 / 32,3$ & $30,1 / 30,3$ & $19,0 / 34,0$ \\
$81-85$ & $41,0 / 26,0$ & $27,0 / 32,0$ & $29,8 / 30,7$ & $17,0 / 35,0$
\end{tabular}

Note: numerator and denominator correspond to rigidity index, $s \mathrm{~N}$, and relative elongation at load of $10 \mathrm{MPa}, \%$

Analysis of the composition of used compositions suggests that the developed technologies are characterized by a reduced flow of filling reagents by $27.0 \%$ compared with the current technology and the minimum use of aerosol A-300 compared with the previously developed aerosol-filling technology [16].

Investigation of the complex of elastic-plastic properties of leather semi-finished chrome tanning using a modifier of collagen structure can testify to their plasticization effect on the structure of the tanned half-finished product. In this case, obviously, the destruction of not only physical interfibrillary bonds, but also chemical bonds between collagen and mucopolysaccharides components of the dermis is happening, which in the absence of bio-catalytic modifiers consolidate the structure of the tanned half-finished, which contributes to its rigidity.

The results of the study of structural-mechanical and technological properties of plasticized BCM-3 semi-finished chrome tiling and filled with reagents with similar control technology, are given in Table 4. According to the obtained data, the leather semi-finished product obtained on the developed technology using a complex biomodifier has a less rigidity and more relative elongation at a load of $10 \mathrm{MPa}$, respectively, 33-47\% and 38-74\% compared with the current technology. This achieves the highest volumetric output of the material and the output of the area. While, according to strength and relative elongation at break, the formed material corresponds to that obtained by the current technology. 
Table 4

Physical and chemical properties of leather semifinished products

\begin{tabular}{|c|c|c|c|}
\hline \multirow{2}{*}{ Indicator } & \multicolumn{3}{|c|}{ The value of the technology indicator } \\
\hline & experimental 1 & experimental 2 & active \\
\hline \multicolumn{4}{|l|}{ Mass fraction, $\%$ : } \\
\hline - moisture & 13,7 & 14,1 & 13,9 \\
\hline - gall substance & 68,9 & 68,1 & 67,7 \\
\hline - salts & 6,5 & 7,6 & 6,7 \\
\hline - Chromium oxide (III) & 4,1 & 4,0 & 4,3 \\
\hline - substances extracted with organic solvents & 6,4 & 6,7 & 7,4 \\
\hline - Organic bonded tannins & 13,8 & 13,9 & 14,7 \\
\hline Semi-finished welding temperature, ${ }^{\circ} \mathrm{C}$ & 113,0 & 113,0 & 111,0 \\
\hline Volume output of skin, $\mathrm{cm}^{3} / 100 \mathrm{~g}$ of GR & 234,0 & 239,0 & 227,0 \\
\hline Sample porosity, $\%$ & 57,0 & 55,0 & 49,0 \\
\hline Air permeability, $\mathrm{cm}^{3} /\left(\mathrm{cm}^{3} / \mathrm{cm}^{2} \cdot\right.$ hour $)$ & 253,0 & 249,0 & 237,0 \\
\hline Tensile strength at stretching, $\mathrm{MPa}$ & 21,7 & 22,5 & 21,3 \\
\hline Relative elongation at a load of $10 \mathrm{MPa}, \%$ & 39,0 & 37,3 & 21,0 \\
\hline Relative elongation at break, $\%$ & 61,0 & 60,0 & 57,0 \\
\hline Hardness of a leather semi-finished product, $\mathrm{sN}$ & 19,0 & 21,0 & 28,0 \\
\hline Output of leather material, $\%$ & 105,1 & 106,7 & 100,0 \\
\hline
\end{tabular}

The addition into the structure of the leather semi-finished product of aerosil during preliminary plasticization of the BCM-3 structure contributes to an increase in the yield of the material's area by $1.6 \%$, and compared with the current technology by $6.7 \%$. This effect may be due to the higher degree of orientation of the elements of the fibrous structure of the leather semi-finished product as a result of its fixation during thermomechanical processing on the model of the 07716/P1 scintillating machine of the Svit firm (Czech Republic).

Thus, the technology of plasticization-filling of leather semi-finished chrome tanning with the use of biocatalytic modifier and highly dispersed aerosil A-300 provides the formation of highly elastic leather material. Bioplasticizing technology for the production of elastic natural materials can be used when filling semi-finished products without chrome tanning at lower temperatures of plasticization. This technology was implemented in the semi-productive conditions of the public JSC "Chynbar".

\section{Conclusions}

1. Effective influence on the elastic-plastic properties of the leather semi-finished product of a biologically catalytic complex modifier is established at a temperature of $71-75{ }^{\circ} \mathrm{C}$ with its consumption of $0.2 \%$ of the mass of the semifinished product.

2. It is shown that when the biocatalytic modifier is effectively used, value of the stiffness index of the semi-finished leather is reduced twice as compared with the semi-finished product, elaborated by the existing technology while maintaining its mechanical strength.

3. It is established that the critical temperature of the plasticization process using biocatalytic modifiers should be done at a temperature of $25-30^{\circ} \mathrm{C}$ below the hydrolytic stability of the leather semi-finished product. At the same time, the initial plasticization of leather semi-finished products is possible in the temperature range $66-80^{\circ} \mathrm{C}$, however, with a decrease of temperature, the duration of the process increases.

4. The developed plasticization process of the leather semi-finished product with the use of biocatalytic modifier 3 provides the formation of natural leather materials with high elastic-plastic properties, with chemical materials saving by $27.0 \%$ and raw materials up to $6.7 \%$ compared to the existing technology. The resulting full of leather material according to the complex of properties corresponds to the elastic leather materials for garments according to DSTU 3115-95, the interstate standard on leather for the top of the footwear "GOST 939-88" and the requirements of the 
international standard of quality management systems "ISO 9001:2008". The authors continue to investigate the establishment of the inhibitory and activating influence of chemical reagents on the drug activity, its effectiveness of processing the semi-finished product, the ingredient composition of the plasticization and filling composition with the participation of new biocatalytic modifiers of the collagen structure and their effective modification of the semifinished chrome tanning.

\section{References}

[1] Wang, C., Feng, S., Wu, J. (2011). Preparation of organosilicone modified palm oil fatliquor. The Journal of the American Leather Chemists Association, 106, 161-169.

[2] New fatliquor for soft articles from TFL. (2011). World Leather, 24 (2), 6.

[3] Leather softening technology. (2009). Leder und Haute Markt, 1, 38.

[4] Shestakova, I. S., Moiseeva, L. V., Miriniva, T. F. (1990). Fermenty v kozhevennom i mechovom proizvodstve. Moscow: Legpromizdat, 128.

[5] Afsar, A., Cetinkaya, F. (2008). Studies on the degreasing of skin by using enzyme in liming process. Indian Journal of Chemical Technology, 15, 507-510.

[6] Ma, J. Z., Lu, H. (2008). Elasticity studies on leather retanned with various types of acrylic polymers. The Journal of the American Leather Chemists Association, 103 (11), 363-369.

[7] Nikitin, M. K., Melnikov, E. P., Suchshkov, A. A., Geller, N. M. (1998). Plastificatsiia kozhi i pergamenta. TPS, 19, 172-174.

[8] Mariliz, G., Silva, D., Vigannico, I. (2010). Leather retanning with hydrolyzed protein. The Journal of the American Leather Chemists Association, 105, 195-202.

[9] Chen, Y., Shi, B. (2011). Nanotechnologies for leather manufacturing: A review. JALCA, 106 (8), 261-273.

[10] Zhang, X., Liu, Q., Zhang, W. (2006). Nanocomposites of acrylate-organsilicon resin/layered silicate for leather finishing. JSLTC, 90 (6), 250-254.

[11] Lischuk, V., Plavan, V., Danylkovych, A. (2006). Transformation of the collagen structure during beam-house processes and combined tanning. Proceedings of the Estonian Academy of Sciences. Engineering, 12 (3-1), 188-198.

[12] Danylkovych, A. H., Chursin, V. I. (2016). Analiticheskii control v proizvodstve kozhi i mekha. Moscow: NITs Infra-M, 175.

[13] Varbanets, L. D., Avdiuk, K. V., Borzova, N. V. Vydilennia, vlastyvosti, praktychne zastosuvannia. StattiOnline. Available at: http://www.stattionline.org.ua/agro/biotehnolog/575-vidilennya-vlastivosti-praktichne-zastosuvannya.html Last accessed: 21.10.2017.

[14] Ailer, R. (1982). Khimiia kremnesema. Part 1. Moscow: Mir, 416.

[15] Aerosil (pirogennii dioksid kremniia). Available at: http://www.silica.su/ru/perechen-produkczii/834-aerosil.pdf. Last accessed: 21.10.2017.

[16] Danylkovych, A. H., Bilinskyi, S. O., Kudziieva, A. Yu. (2016). Vykorystannia vysokodyspersnoho oksydu kremniiu v tekhnolohii vyhotovlennia shkirianoho napivfabrykatu. Visnyk Khmelnytskoho natsionalnoho universytetu. Tekhnichni nauky, 6 (243), 112-116. 